\title{
Andreas Pollak
}

\section{Optimal Unemployment Insurance}

[Optimale Arbeitslosenversicherung.]

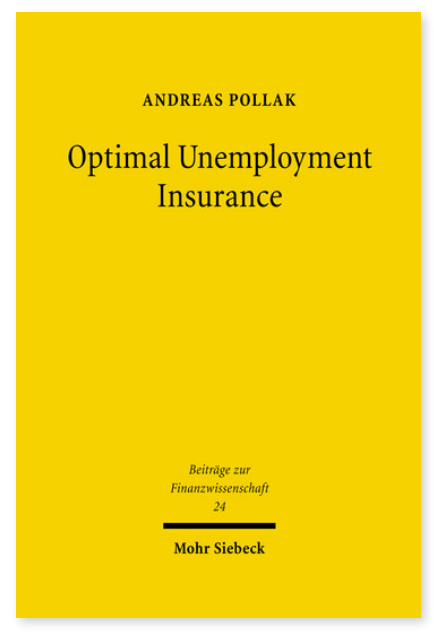

2007. XI, 178 Seiten. BtrFin 24

SBN 978-3-16-151074-8

DOI 10.1628/978-3-16-151074-8

eBook PDF 109,00€

ISBN 978-3-16-149304-1

Leinen $109,00 €$
Veröffentlicht auf Englisch.

Ein Arbeitslosenversicherungssystem zu gestalten ist eine schwierige Aufgabe. Wählt man ein geringes Leistungsniveau, sind die betroffenen Haushalte mitunter einem ineffizient hohen Einkommensrisiko ausgesetzt. Auf der anderen Seite führen übermäßig großzügige Versicherungsleistungen zu einem hohen Arbeitslosigkeitsniveau, was zu erheblichen fiskalischen und gesellschaftlichen Belastungen führt. Andreas Pollak geht der Frage nach, wie eine optimale Arbeitslosenversicherung aussehen würde, also ein System, das den bestmöglichen Kompromiss zwischen Einkommenssicherung und Arbeitsanreizen darstellt. Mit Hilfe ökonomischer und ökonometrischer Modelle untersucht er u.a., welche Auswirkungen die Höhe und die Bezugsdauer der Versicherungsleistungen auf die Arbeitslosigkeit und die Wohlfahrt haben. In numerischen Simulationen werden effiziente Versicherungen unter verschiedenen Annahmen bestimmt.

Andreas Pollak Born 1978; studied Economics (VWL) at the University of Freiburg and the London School of Economics; Computer Science at FernUni Hagen; 2006 PhD in Economics (Promotion in VWL), University of Freiburg.

Jetzt bestellen:

https://mohrsiebeck.com/buch/optimal-unemployment-insurance-9783161510748?no cache=1

order@mohrsiebeck.com

Telefon: +49 (0)7071-923-17

Telefax: $+49(0) 7071-51104$ 